\title{
Functional Coatings and Microencapsulation: A General Perspective
}

\author{
Swapan Kumar Ghosh
}

\section{1}

\section{An Overview of Coatings and Paints}

Today, many objects that we come across in our daily lives, including the house in which we live and the materials we use (e.g., toothbrushes, pots and pans, refrigerators, televisions, computers, cars, furniture) all come under the "umbrella" of coated materials. Likewise, fields such as military applications - for example, vehicles, artilleries and invisible radars - and aerospace products such as aircraft, satellites and solar panels all involve the widespread use of coated materials. Clearly, the importance of coatings has increased hugely during the modern era of technology.

Coating is defined as a material (usually a liquid) which is applied onto a surface and appears as either a continuous or discontinuous film after drying. However, the process of application and the resultant dry film is also regarded as coating [1]. Drying of the liquid coating is mostly carried out by evaporative means or curing (cross-linking) by oxidative, thermal or ultraviolet light and other available methods. Paint can be defined as a dispersion that consists of binder(s), volatile components, pigments and additives (catalyst, driers, flow modifiers) [2]. The binder (polymer or resin) is the component that forms the continuous film, adheres to the substrate, and holds the pigments and fillers in the solid film. The volatile component is the solvent that is used for adjusting the viscosity of the formulation for easy application. Depending on their compositions, paints can be divided into three groups: solvent-borne, water-borne and solvent-free (100\% solid). Solvent-borne paints consist of resin, additives and pigments that are dissolved or dispersed in organic solvents. Similarly, in water-borne paints the ingredients are dispersed in water. In solvent-free compositions, the paints do not contain any solvent or water and the ingredients are dispersed directly in the resin.

The properties of coating films are determined by the types of binders, pigments and miscellaneous additives used in the formulation. Moreover, types of substrates, substrate pretreatments, application methods and conditions of film formation 
play additional roles in determining the end properties of the coating. The terms "coating" and "paint" will be used synonymously in this book. In general, collectively or individually, paints, varnishes (transparent solutions) and lacquers (opaque or colored varnishes) are termed as coatings [3].

Coatings occur in both organic and inorganic forms. Inorganic coatings are mainly applied for protective purposes, while organic coatings are mostly used for decorative and functional applications [4]. Organic coatings can be classified as either architectural coatings (house, wall and ceiling coatings) or industrial coatings (appliances, furniture, automobiles, coil coatings) [3]. Although organic and inorganic coatings may be used individually for industrial applications, for specific requirements a combination of both systems - termed hybrid coating - is favored.

\section{2}

\section{Classification of Coating Properties}

Coatings are usually applied as multi-layered systems that are composed of primer and topcoat. However, in some cases - for example automotive coating systems this may vary from four to six layers. Each coating layer is applied to perform certain specific functions, though its activities are influenced by the other layers in the system. The interactions among different layers and the interfacial phenomenon play an important role in the overall performance of the multi-coat systems [5]. Different properties of coatings are typically associated with specific parts of a coating system (Fig. 1.1) [6].

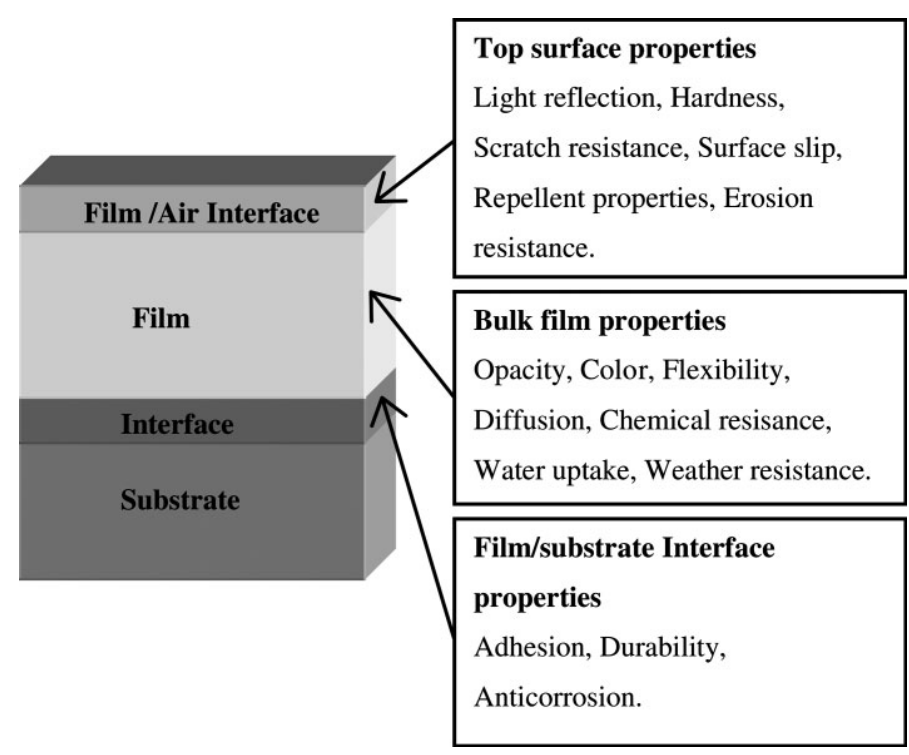

Figure 1.1 Topographical classification of coating properties. 


\section{3}

\section{What are Functional Coatings?}

Coatings are mainly applied on surfaces for decorative, protective, or functional purposes, but in most cases it is a combination of these. The term "functional coatings" describes systems which possess, besides the classical properties of a coating (i.e., decoration and protection), an additional functionality [7]. This additional functionality may be diverse, and depend upon the actual application of a coated substrate. Typical examples of functional coatings are self-cleaning [8,9], easy-toclean (anti-graffiti) [10], antifouling [11], soft feel [12] and antibacterial [13-15]. Although various mechanisms are involved, as well as numerous applications, there is a common feature that is of particular benefit and which satisfies some users' demands. Most coatings (whether inorganic, organic or ceramic) perform critical functions, but as these fields are extensive it is beyond the scope of this book to include all of them at this stage. Thus, the discussion here is limited to coatings with organic binders.

\section{4}

\section{Types and Application of Functional Coatings}

Apart from their special properties, functional coatings must often satisfy additional requirements; for example, nonstick cookware coatings must be resistant to scratching, abrasion and thermal effects. Typical expectations of functional coatings include:

- durability

- reproducibility

- easy application and cost effectiveness

- tailored surface morphology

- environmental friendliness

Functional coatings can be classified as several types depending on their functional characteristics (Fig. 1.2).

Functional coatings perform by means of physical, mechanical, thermal and chemical properties. Chemically active functional coatings perform their activities either at film-substrate interfaces (anticorrosive coatings), in the bulk of the film (fire-retardant or intumescent coatings), or at air-film interfaces (antibacterial, self-cleaning) [16].

Some applications of functional coatings are discussed in the following sections. 


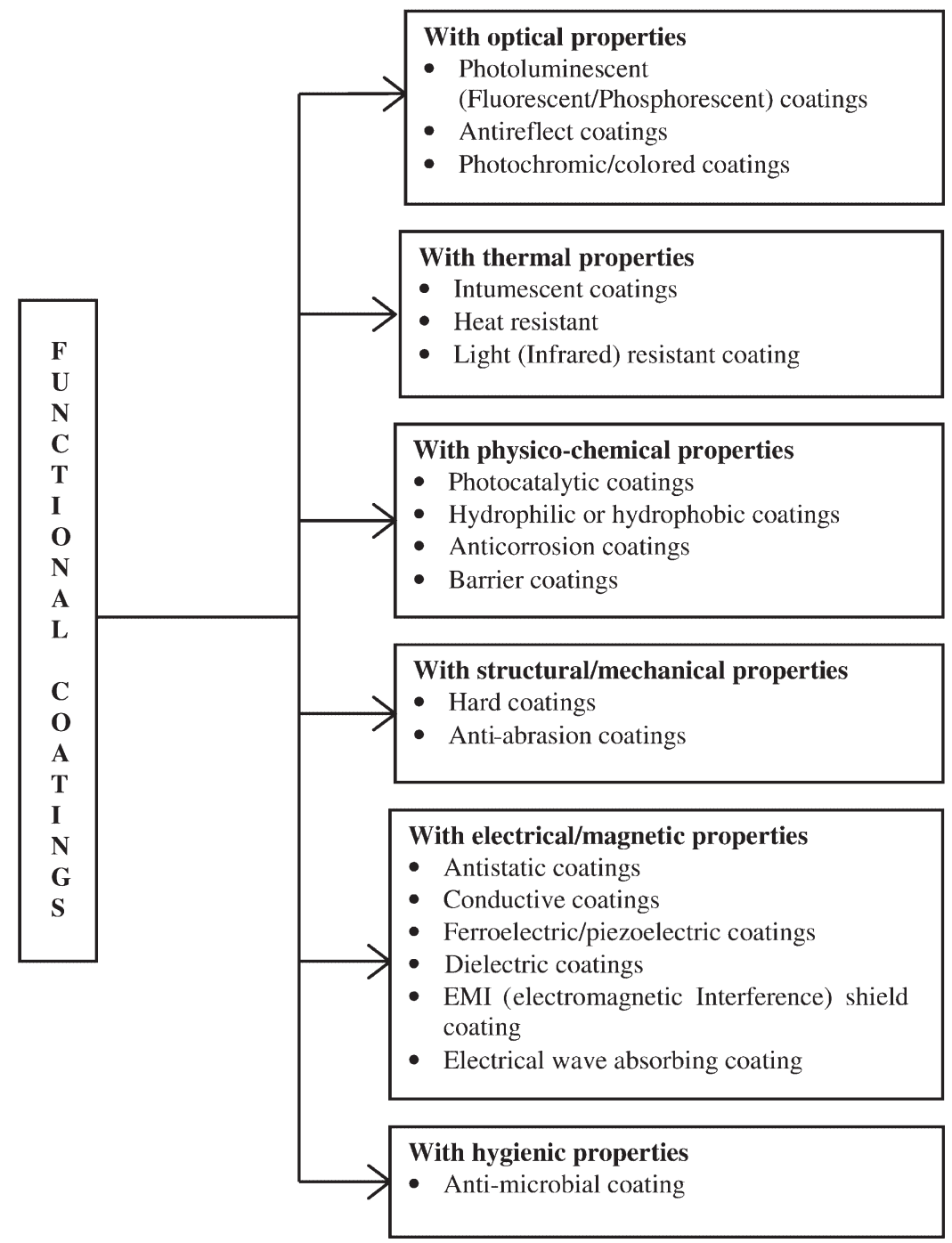

Figure 1.2 Types of functional coatings.

\subsection{1}

\section{Anticorrosive Coatings}

It is known that, when iron is exposed to a natural atmosphere, then rust is formed. Although the rusting of iron or steel is usually termed as corrosion, the latter is a general term which is used to define the destructive interaction of a material with its environment. Corrosion usually refers to metals, though nonmetallic substrates such as plastics, concrete or wood also deteriorate in the environment. Corrosion causes enormous industrial losses with a depletion of our natural resources. When 
two areas of a metallic component are exposed to different operational environments, or they differ in their surface structure or composition, an electrical potential is developed. Corrosion is in fact an electrochemical process where the electrical cell is composed of an anode (the corrosion site), an electrolyte (the corrosive medium), and a cathode (part of the metal which is active in the corrosion process but does not itself corrode) [17].

In general, organic coatings are applied onto metallic substrates in order to avoid the detrimental effect of corrosion. The anticorrosive performance of the coating depends upon several parameters, including: adhesion to metal, thickness, permeability, and the different properties of the coating. In most cases, the primer is mainly responsible for protecting the metallic substrate and adhering to other coating layers. In this context, surface preparation is essential in order to provide good adhesion of the primer to the metallic substrate [18]. The mechanisms by which organic coatings offer corrosion protection are summarized as follows.

- Sacrificial means: The use of a sacrificial anode such as zinc to protect steel is a longstanding and well-known industrial practice. The zinc layer on galvanized steel degrades when exposed to an adverse environment, and this protects the underneath surface. Using a similar approach, both inorganic and organic resinbased, zinc-rich coatings have been developed to protect a variety of metal substrates $[19,20]$.

- Barrier effect: In general, polymeric coatings are applied to metallic substrates to provide a barrier against corrosive species. They are not purely impermeable. Moreover, defects or damages in the coating layer provide pathways by which the corrosive species may reach the metal surface, whereupon localized corrosion can occur. Pigments having lamellar or plate-like shapes (e.g., micaceous iron oxide and aluminum flakes) are introduced to polymeric coatings; this not only increases the length of the diffusion paths for the corrosive species but also decreases the permeability of the coating [21]. Other pigments such as stainless steel flakes, glass flakes and mica are also used for this purpose. The orientation of the pigments in the coating must be parallel to the surface, and they should be highly compatible with the matrix resin to provide a good barrier effect. Layered clay platelets such as montmorillonite may also be introduced into organic resin systems to increase the barrier effect towards oxygen and water molecules, thereby enhancing the anticorrosive performance of the coating (Fig. 1.3) [22].

- Inhibition: Traditionally, chromate- and lead-based pigments are the most common compounds used as corrosion inhibitors to formulate anticorrosive primers for metallic substrates. These substances are considered to be toxic and ecologically unsafe, and therefore the search for new alternative anticorrosive pigments is under way. Today, primers containing metallic phosphate, silicate, titanate or molybdate compounds are available commercially. These pigments form a protective oxide layer on the metallic substrates, and often also form anticorrosive complexes with the binder. To reduce the cost, a number of elements and compounds have been combined to develop an effective anticorrosive pigment, including aluminum zinc phosphate, calcium zinc molybdate, zinc molybdate 


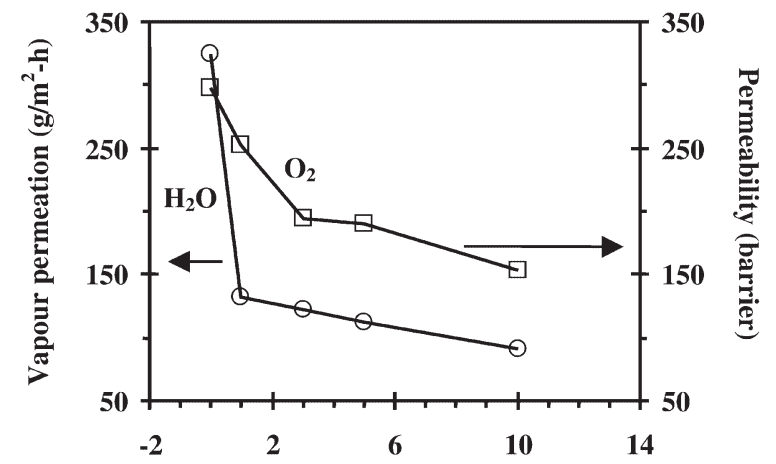

Amount of clay (wt \%) in the nanocomposite

Figure 1.3 Permeability of water $\left(\mathrm{H}_{2} \mathrm{O}\right)$ and oxygen $\left(\mathrm{O}_{2}\right)$ as a function of clay (montmorillonite) content in polystyrene-clay nanocomposite material (adapted from [22]).

phosphate, calcium borosilicate, and strontium phosphosilicate. Organofunctional silanes have emerged recently as alternative chromate treatments for metals due to their environmental friendliness and good anticorrosion properties [23]. The main disadvantage of using silane is that the substrate must bear hydroxyl groups on its surface. Thus, silane technology offers less flexibility compared to the titanate-based chemistry [24]. Another modern development is the use of intrinsically conductive polymers (ICPs) in the corrosion protection of metals (see Chapter 6) [25,26]. A different approach is the use of core-shell materials (e.g., a ferric oxide core with a shell of zinc phosphate or anticorrosive titanium dioxide coated with an organic polymer) to develop anticorrosive primers $[27,28]$. Self-priming, chromate-free, corrosion-resistant coating compositions have also been investigated [29]. Smart corrosion-inhibiting coatings such as the inclusion of a $\mathrm{pH}$ indicator into a paint formulation that can cause color change when corrosion occurs are presently under investigation. Recent developments also include the use of nanoclay that can exchange anticorrosive agents with the corrosive species when needed. Although these innovative research projects have not yet provided any new commercial products, they offer a variety of interesting routes for future developments.

\subsection{2}

\section{High Thermal-Resistant and Fire-Retardant Coatings}

High thermal-resistant coatings are required for a wide variety of metallic substrates that we encounter in everyday life, including nonstick cookware, barbecues and boilers. Fluorine- or silicon-based products are used to obtain a high thermal resistance for the above-mentioned products. Fluorinated coatings are not suitable for high-temperature applications as they degrade above $\sim 300^{\circ} \mathrm{C}$ and produce toxic byproducts. Although other binders such as phenolic or epoxy are used to pre- 
pare high thermal-resistant coatings, at present silicon-containing coatings dominate the market. Silicon-containing polymers offer better thermal resistance due to the high energy required to cleave silicon bonds compared to carbon bonds in analogous molecules. Recently developed silicon-based coatings are able to resist temperatures of up to $1000^{\circ} \mathrm{C}$. Silicon derivatives such as silicone resins (siloxanes) or inorganic silicates are commonly used for high-temperature applications.

Silicon-containing materials are expensive, however, and consequently copolymers or blends of silicones with acrylate, epoxy or urethanes are very often used to save costs. Recent reports have been made of innovative ways to design thermal-resistant coatings; for example, titanium esters in combination with aluminum flakes have been incorporated into binders that resist temperatures up to $400{ }^{\circ} \mathrm{C}$. Above this temperature "burn off" occurs and a complex coating of titanium-aluminum is formed that deposits on the substrate and enhances thermal resistance up to $800^{\circ} \mathrm{C}$ [30].

The devastating nature of fire creates havoc and results in great loss of lives and property. Thus, the need to develop fire-retardant coatings is constantly growing. Although protection against fire by the use of coatings for indefinite periods is impossible, the use of fire-retardant coatings can delay the spread of fire or keep a structure intact against fire, thereby allowing sufficient time for safety measures to be taken. Today, several types of fire retardant are available, including phosphoruscontaining, halogen-based and intumescent fire-retardant systems, each with a different principle of operation. Phosphorus-containing compounds function by forming a protective layer either as a glassy surface barrier or by producing char. Halogen- and antimony-based fire retardants are both toxic and ecologically unsafe.

Intumescent coatings form an expanded carbonaceous char which acts as a protective barrier against heat transfer and hinders the diffusion of combustible gases and melted polymer to the site of combustion. These coatings are composed of three components: (i) an inorganic acid (dehydrating agent); (ii) a carbonaceous char-forming material; and (iii) a blowing agent. The performance of the intumescent system depends on the choice of the ingredients and their appropriate combination [31,32]. Nowadays, expandable graphites are available commercially as fireretardant agents; these contain chemical compounds, including an acid, entrapped between the carbon layers. Upon exposure to higher temperatures, exfoliation of the graphite takes place and this provides an insulating layer to the substrate [33]. A combination of polyurethane and phosphate serves as a well-known fire-retardant intumescent system. One problem associated with these systems results from the solubility of phosphates in water, and this leads to problems of migration. Nonetheless, this difficulty can be avoided by encapsulating phosphates (di-ammonium hydrogen phosphate) within a polyurethane shell and, indeed, the use of microencapsulated fire retardants in polyurethane coatings has shown good fire resistance [34]. Today, silicon- or inorganic hydroxide-based fire-retardant coatings are used in a wide variety of industrial applications [35,36]. Recently, polymer clay (layered silicates) nanocomposites have also been explored for the development of fire-retardant coatings [37,38]. 


\section{4 .3}

\section{Scratch- and Abrasion-Resistant Coatings}

Coatings are susceptible to damage caused by scratch and/or abrasion. Clearly, the consumer prefers to retain the aesthetic appearance of coated materials, and for this reason clear coats used on automobiles must have good scratch and abrasion resistance. An added problem is that scratches may also cause damage to the underlying substrate.

Many companies worldwide have undertaken the challenge of improving the scratch resistance of a coating, without adversely affecting its other properties. Scratch resistance can be obtained by incorporating a greater number of crosslinks in the coating's binder, but unfortunately highly crosslinked (hard) films have poor impact resistance due to less flexibility. A less-crosslinked (softer) film will show better performance with regard to other properties such as anti-fingerprint and impact resistance, but will have less scratch and abrasion resistance. Thus, in order to

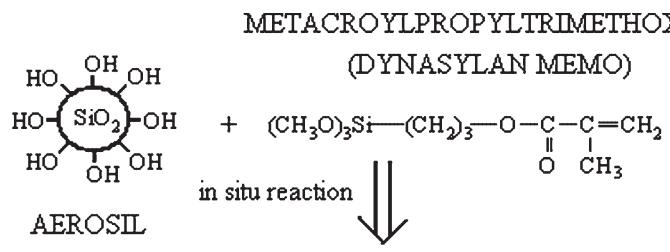

SIMA

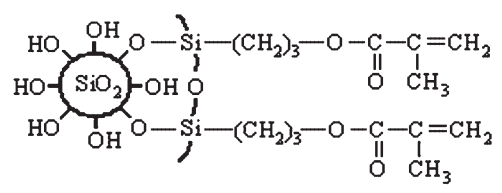

Radiation curing (UV, EB) in acrylate dispersion

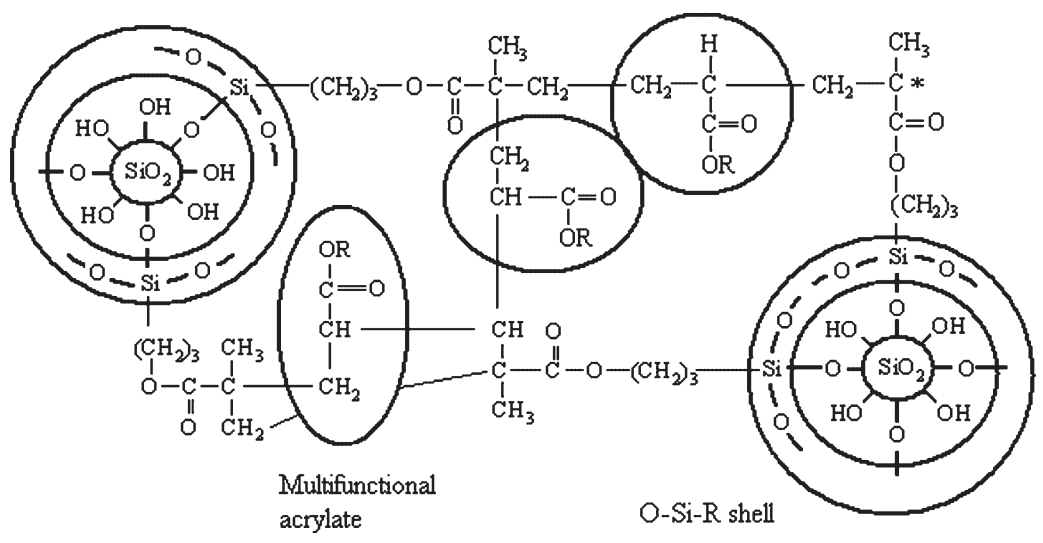

Figure 1.4 Schematic structure of grafted silica nanoparticles and radiation-cured grafted silica/acrylate networks (adapted from reference [41]). 
obtain optimal scratch resistance the correct combination of hardness and flexibility is required. In this context, organic-inorganic hybrid films are paving the way for scratch-resistant coating developments. Recent advances in nanotechnology plays an important role in the development of scratch-resistant coatings [39,40]. Gläsel et al. have shown the use of siloxane-encapsulated $\mathrm{SiO}_{2}$ nanoparticles to develop scratch- and abrasion-resistant coatings [41,42] (Fig. 1.4).

PPG industries have developed scratch-resistant coatings by incorporating $\mathrm{SiO}_{2}$ nanoparticles into an organic matrix that can migrate to the surface. In this way the scratch resistance is enhanced due to an enrichment of the nanoparticles near the coating surface [43]. Coatings with good abrasion and scratch-resistant properties have also been reported by others $[44,45]$.

\section{4 .4}

\section{Self-Cleaning Coatings}

Self-cleaning coatings, as the name suggests, have a special functional property, and today the term Lotus effect ${ }^{\circledR}$ and self-cleaning are synonymous. Although these surfaces can be soiled, manual cleaning is unnecessary and a shower of rain is sufficient to carry out the cleaning process. In 1997, Barthelott and coworkers showed that the self-cleaning property of lotus leaves was due to their specialized surface morphology and hydrophobicity [46] (Fig. 1.5a).

This specialized morphology prevents dirt from forming an intimate contact with the surface, while the high hydrophobicity makes the leaf water-repellent. Consequently, as the water droplets roll onto the leaf surface, they carry along the contaminants (Fig. 1.5b). Since the initial discovery by Barthelott, many groups have attempted to mimic this activity to develop self-cleaning or lotus-effect coatings [47]. Detailed discussions on this concept, the underlying mechanism and the different applications of self-cleaning coating surfaces can be found elsewhere
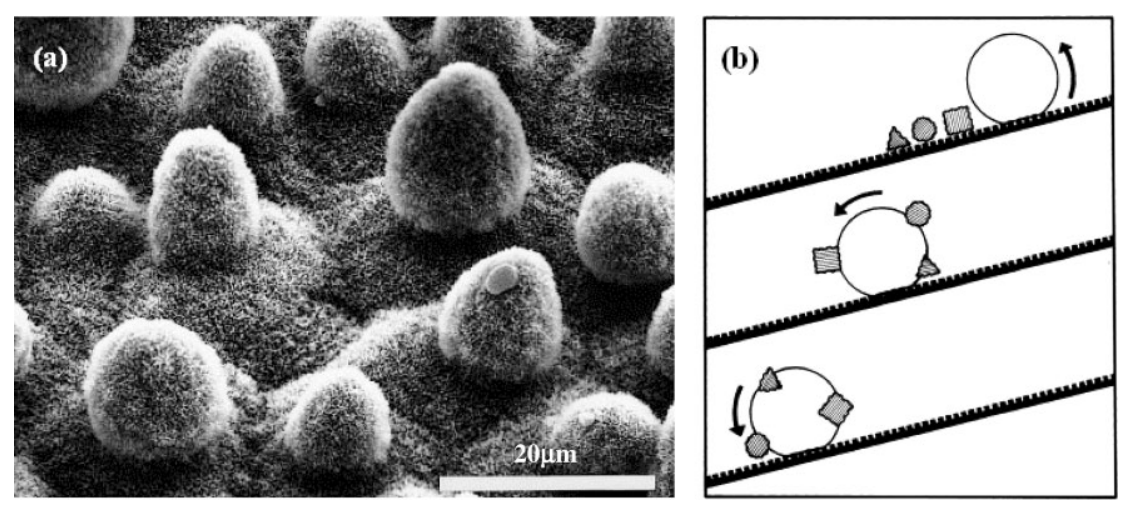

Figure 1.5 (a) Scanning electron micrograph of lotus leaf. (b) Schematic depicting the relationship between surface roughness and self-cleaning (adapted from [46], with kind permission of Springer Science and Business Media. 
$[9,48,49]$. One very recent report noted that lotus leaves may be either hydrophilic or hydrophobic, depending on the contact of water molecules at the leaf surface [50].

During the past few years, self-cleaning coatings using photocatalytic titanium dioxide $\left(\mathrm{TiO}_{2}\right.$; especially the anatase crystalline form) have attracted considerable attention both in academic and industrial sectors. When photocatalytic $\mathrm{TiO}_{2}$ particles are illuminated with an ultraviolet light source (e.g., sunlight), electrons are seen to be promoted from the valence band (VB) to the conduction band (CB) of the particle [51,52]. This creates a region of positive charge $\left(\mathrm{h}^{+}\right)$, holes, in the VB and a free electron in the CB. These charge carriers can either recombine or migrate to the surface, while the holes can react with the hydroxyl or adsorbed water molecules on the surface and produce different radicals such as hydroxyl radicals $(\mathrm{OH} \cdot)$ and hydroperoxy radicals $\left(\mathrm{HO}_{2} \cdot\right)$. By contrast, the electrons combine with the oxygen and produce superoxide radicals. These photo-produced radicals are powerful oxidizing species and can cause the deterioration of organic contaminants or microbial species on the particle surface. The other beneficial effect of $\mathrm{TiO}_{2}$ is its super hydrophilic behavior, commonly known as the "water sheathing effect" [53]. This allows contaminants to be easily washed away with water or rainfall if the coatings are applied to external surfaces. Both photocatalysis and hydrophilicity occur simultaneously, despite their underlying mechanisms being of an entirely different nature. The addition of silicon oxide to $\mathrm{TiO}_{2}$ has also been shown to enhance the overall self-cleaning properties [54].

Photocatalytic $\mathrm{TiO}_{2}$ particles cannot be incorporated or deposited on the organic coating, as they oxidize the polymer. Recent developments have revealed the use of $\mathrm{TiO}_{2}$ particles in combination with organic resins [55-57].

\subsection{5}

\section{Antibacterial Coatings}

In today's world, reports of outbreaks of disease in hospitals or problems caused by food poisoning are all-too-frequent occurrences. Microorganisms such as bacteria, fungi or viruses represent potential threats for our modern hygienic lifestyle. Microbial growth on coated substrates may have several adverse consequences, including problems of aesthetics (discoloration of the coating), risks to health and hygiene, malodor, biofilm development or microbial corrosion in the case of metallic substrates. Organic coatings are susceptible to microbial attack, and the properties of the coating and its composition, the presence of nutrients on the surface and the nature of substrates represent the main parameters that determine the types of microorganisms able to colonize the coating. A schematic representation of biofilm formation by microorganisms is shown in Figure 1.6.

The classical biocides function either by inhibiting the growth of bacteria (biostatic) or by killing them (biocidal) (Fig. 1.6). However, new legislations, combined with growing pressure from the environmentalists and the possibility of bacterial mutation have forced coating manufacturers to seek new alternatives. Today, more emphasis is placed on the development of biorepulsive (without killing) antibacterial coatings. 


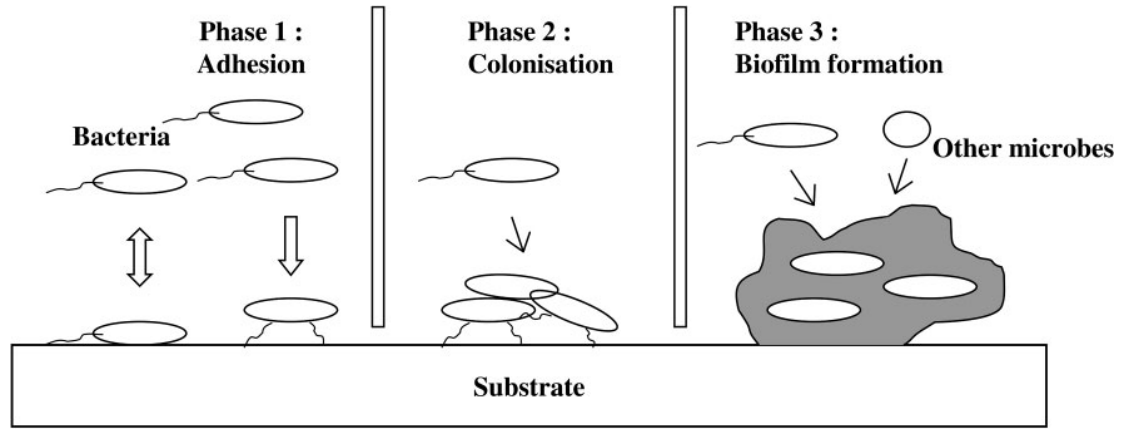

Figure 1.6 Schematic of biofilm formation by microorganisms.

A wide variety of organic or inorganic biocides are available commercially, and these demonstrate a wide variety of biocidal and biostatic mechanisms [58]. For example, biocides containing heavy metal ions function by penetrating the cell wall and inhibiting the bacterium's metabolic enzymes, whereas antimicrobial agents with cationic surfaces cause rupture of the bacterium's cytoplasmic membrane. Examples of organic biocides include polymers, tertiary alkyl amines and organic acids $[59,60]$, while inorganic biocides include silver, zinc oxide (ZnO), copper oxide $(\mathrm{CuO}), \mathrm{TiO}_{2}$, and selenium [61-66]. Microcapsules containing biocides have also been developed in order to increase the longevity and efficiency of antimicrobial coatings [67-69].

\section{4 .6}

\section{Antifouling Coatings}

Marine organisms represent a major threat to all objects used within a marine environment, and the unwanted growth or deposition of such organisms being termed as "fouling". Fouling is generally more prominent in coastal waters where ships or boats are either docked or travel at slow speed. Depending upon the types of marine organism involved, fouling is of two main types, namely microfouling and macrofouling.

Microfouling is caused by diatoms and bacteria, whereas macrofouling is caused by marine animals (barnacles, tubeworms) and plants (algae). Both biocidal and nonbiocidal coatings are used to prevent foulings. Biocide-based antifouling coatings function by slow leaching of the incorporated biocides into the coating. For reasons of stringent legislation and toxicity, the use of biocides is restricted on a daily basis. For example, tributyl tin (TBT) is a highly efficient marine biocide, but it is no longer used due to its toxicity. It is important that the biocide does not have any adverse effects on marine life while carrying out its antifouling activity. For long-term antifouling effects, either controlled-release or contact-active biocides are required [70].

Recently, a number of antifouling products have been developed using microencapsulation technology [71,72]. For the nonbiocidal approach, polymers with low 
surface energy are used in order to avoid the adhesion of marine organisms, and silicone elastomers are widely used for this purpose. However, this approach is only effective when the vessels move at relatively high speeds, for example ferries.

The specialized applications of coatings are almost unlimited, and developments of special effect pigments offer new possibilities for the design of functional coatings $[73,74]$. In this context, infrared (IR)-reflective pigments are in great demand for the development of "cool roof" coatings, while ultraviolet (UV)-resistant coatings have been developed for outdoor applications [75]. Water-borne functional coatings are becoming more popular than the solvent-borne systems due to their eco-friendly behavior [76].

\section{5}

\section{Microencapsulation}

The encapsulation of materials has evolved from examples in Nature, wherein numerous examples exist, ranging from macroscale to nanoscale. Nature envelops materials to protect them from environmental influences; the simplest example on a macroscopic scale is a bird's egg or a seed, while on a microscopic scale the best example is that of a cell along with its contents [77]. The development of microencapsulation began with the preparation of capsules containing dyes; these were incorporated into paper for copying purposes and replaced carbon paper [78]. The pharmaceutical industry has long used microencapsulation for the preparation of capsules containing active ingredients, though as time passed a variety of new technologies have emerged and are being developed in many fields of research. During the past 10 years this approach has been explored widely by the agricultural, food, cosmetic, and textile industries. Microencapsulation provides the possibility of combining the properties of different types of material (e.g., inorganic and organic) - a process which is difficult to achieve using other techniques. Although microencapsulation offers great potential in the coating industry, very little development has been carried out to date in this area. Extended reviews of microencapsulation techniques and processes can be found in references [79-83].

Microencapsulation cannot be defined as a product or as a component of a product. Rather, it is described as a process of enclosing micron-sized particles of solids or droplets of liquids or gasses in an inert shell, which in turn isolates and protects them from the external environment. The inertness is related to the reactivity of the shell with the core material. This technology is mainly used for the purpose of protection, controlled release, and compatibility of the core materials (see Chapter 7).

\section{6}

\section{Microcapsules}

The resultant product of the microencapsulation process is termed a "microcapsule". Such capsules are of micrometer size $(>1 \mu \mathrm{m})$, and have a spherical or ir- 


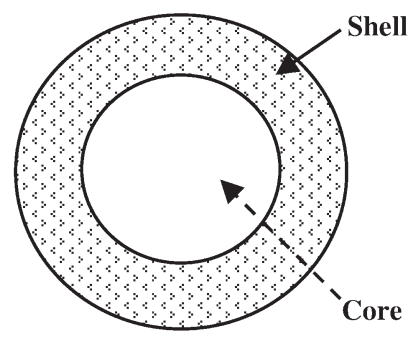

Figure 1.7 Schematic of microcapsule.

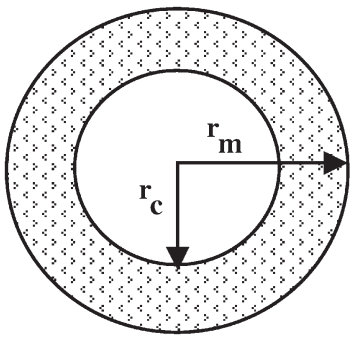

Figure 1.8 Cross-section of an idealized microcapsule.

regular shape. Microcapsules can be divided into two parts, namely the core and the shell. The core (the intrinsic part) contains the active ingredient (e.g., a hardener or a biocide), while the shell (the extrinsic part) protects the core permanently or temporarily from the external atmosphere. A microcapsule is shown schematically in Figure 1.7.

Core materials in microcapsules may exist in the form of either a solid, liquid or gas. The core materials are used most often in the form of a solution, dispersion or emulsion. Compatibility of the core material with the shell is an important criterion for enhancing the efficiency of microencapsulation, and pretreatment of the core material is very often carried out to improve such compatibility. The size of the core material also plays an important role for diffusion, permeability or controlledrelease applications. Depending on applications, a wide variety of core materials can be encapsulated, including pigments, dyes, monomers, catalysts, curing agents, flame retardants, plasticizers and nanoparticles.

The abundance of natural and man-made polymers provides a wider scope for the choice of shell material, which may be made permeable, semi-permeable or impermeable. Permeable shells are used for release applications, while semi-permeable capsules are usually impermeable to the core material but permeable to low molecular-weight liquids. Thus, these capsules can be used to absorb substances from the environment and to release them again when brought into another medium. The impermeable shell encloses the core material and protects it from the external environment. Hence, to release the content of the core material the shell must be ruptured by outside pressure, melted, dried out, dissolved in solvent or degraded under the influence of light (see Chapter 7). Release of the core material through the permeable shell is mainly controlled by the thickness of the shell wall and its pore size. The dimension of a microcapsule is an important criterion for industrial applications; the following section will focus on spherical core-shell types of microcapsules (Fig. 1.8).

Assuming that the density of the core $\left(\rho_{c}\right)$ and shell $\left(\rho_{s}\right)$ materials are identical (i.e., $\rho_{\mathrm{c}}=\rho_{\mathrm{s}}$ ), it is possible to establish the relationship between the shell thickness $\left(d_{s}=r_{m}-r_{c}\right)$ and the ratio of the weight of the shell material $\left(w_{s}\right)$ to that of the core material $\left(\mathrm{w}_{\mathrm{c}}\right)$ :

$$
\frac{\boldsymbol{w}_{s}}{\boldsymbol{w}_{c}}=\frac{(4 / 3) \pi\left(\boldsymbol{r}_{m}^{3}-\boldsymbol{r}_{c}^{3}\right) \cdot \rho_{s}}{(4 / 3) \pi \boldsymbol{r}_{c}^{3} \cdot \rho_{s}}
$$


After rearranging, the following equation is obtained:

$$
\boldsymbol{d}_{s}=\left(\boldsymbol{r}_{m}-\boldsymbol{r}_{c}\right)=\left[\left(\frac{\boldsymbol{w}_{s}}{\boldsymbol{w}_{c}}+1\right)^{1 / 3}-1\right] \boldsymbol{r}_{c}
$$

Equation (2) shows a linear relationship between the shell thickness and the capsule diameter when the ratio of $\mathrm{w}_{\mathrm{c}} /\left(\mathrm{w}_{\mathrm{s}}+\mathrm{w}_{\mathrm{c}}\right)$ is in the range of 0.50 to 0.95 [83].

\section{7}

\section{Morphology of Microcapsules}

The morphology of microcapsules depends mainly on the core material and the deposition process of the shell. Microcapsules may have regular or irregular shapes and, on the basis of their morphology, can be classified as mononuclear, polynuclear, and matrix types (Fig. 1.9).

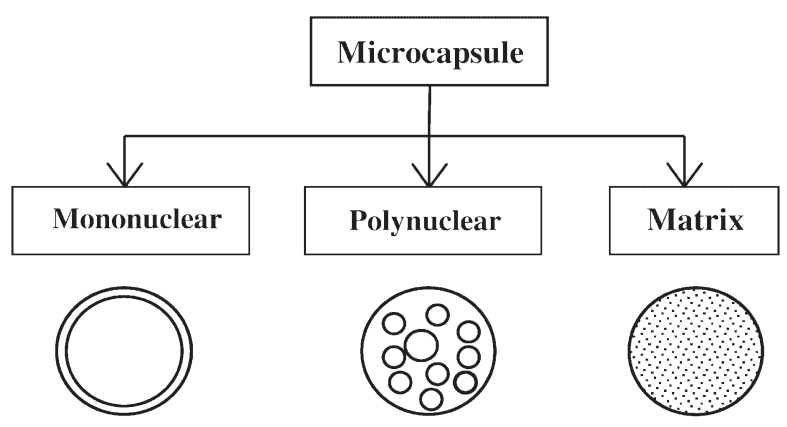

Figure 1.9 Morphology of microcapsules.

Mononuclear (core-shell) microcapsules contain the shell around the core, while polynuclear capsules have many cores enclosed within the shell. In matrix encapsulation, the core material is distributed homogeneously into the shell material. In addition to these three basic morphologies, microcapsules can also be mononuclear with multiple shells, or they may form clusters of microcapsules.

\section{8}

\section{Benefits of Microencapsulation}

Microcapsules have a number of interesting advantages, and the main reasons for microencapsulation can be summarized as follows:

- Protection of unstable, sensitive materials from their environments prior to use.

- Better processability (improving solubility, dispersibility, flowability). 
- Self-life enhancement by preventing degradative reactions (oxidation, dehydration).

- Controlled, sustained, or timed release.

- Safe and convenient handling of toxic materials.

- Masking of odor or taste.

- Enzyme and microorganism immobilization.

- Controlled and targeted drug delivery.

- Handling liquids as solids.

\section{9}

\section{Microencapsulation Techniques}

Numerous preparation technologies available for the encapsulation of core material have been reported $[81,82,84]$. The present discussion focuses on the different microencapsulation techniques that are more relevant to the coating industries, and also provides a comprehensive review of recently developed methods. In general, microencapsulation techniques are divided into two basic groups, namely chemical and physical, with the latter being further subdivided into physico-chemical and physico-mechanical techniques. Some of the important processes used for microencapsulation are summarized in Table 1.1.

Table 1.1 Different techniques used for microencapsulation.

\begin{tabular}{lll}
\hline Chemical processes & $\begin{array}{l}\text { Physical processes } \\
\text { Physico-chemical }\end{array}$ & Physico-mechanical \\
\hline - Suspension, dispersion & - Coacervation & - Spray-drying \\
and emulsion & - Layer-by-layer & - Multiple nozzle spraying \\
polymerization & (L-B-L) assembly & - Fluid-bed coating \\
- Polycondensation & - Sol-gel encapsulation & - Centrifugal techniques \\
& - Supercritical $\mathrm{CO}_{2}$-assisted & - Vacuum encapsulation \\
& microencapsulation & $\bullet$ Electrostatic encapsulation \\
\hline
\end{tabular}

\subsection{1}

\section{Chemical Methods}

In-situ processes such as emulsion, suspension, precipitation or dispersion polymerization and interfacial polycondensations are the most important chemical techniques used for microencapsulation [85-90]. An image of microcapsules with an aqueous core and silicone shell prepared using in-situ polymerization is shown in Figure 1.10.

An in-depth discussion on the major in-situ polymerization processes is provided in Chapter 4. In addition, encapsulation using the mini emulsion process is discussed in Chapter 2, and interfacial polycondensations processes are described in Chapter 5 . 


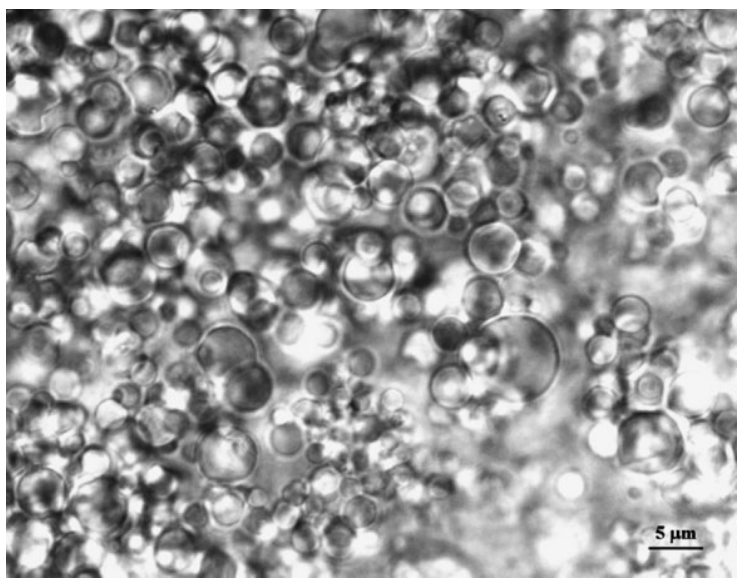

Figure 1.10 Scanning electron micrograph of silicone microcapsules containing an aqueous solution of self-tanning composition (Courtesy: G. Habar, Microcapsules-Technologies).

\section{9 .2}

\section{Physico-Chemical Processes}

\subsubsection{Coacervation}

The first systematic approach of phase separation - that is, partial desolvation of a homogeneous polymer solution into a polymer-rich phase (coacervate) and the poor polymer phase (coacervation medium) - was realized by Bungenberg and colleagues $[91,92]$. These authors termed such a phase separation phenomenon "coacervation". The term originated from the Latin >acervus< , meaning "heap". This was the first reported process to be adapted for the industrial production of microcapsules.

Currently, two methods for coacervation are available, namely simple and complex processes. The mechanism of microcapsule formation for both processes is identical, except for the way in which the phase separation is carried out. In simple coacervation a desolvation agent is added for phase separation, whereas complex coacervation involves complexation between two oppositely charged polymers.

\section{Complex coacervation}

Complex coacervation is carried out by mixing two oppositely charged polymers in a solvent (usually water); the process is shown schematically in Figure 1.11.

The three basic steps in complex coacervation are: (i) preparation of the dispersion or emulsion; (ii) encapsulation of the core; and (iii) stabilization of the encapsulated particle. First the core material (usually an oil) is dispersed into a polymer solution (e.g., a cationic aqueous polymer). The second polymer (anionic, watersoluble) solution is then added to the prepared dispersion. Deposition of the shell material onto the core particles occurs when the two polymers form a complex. This process is triggered by the addition of salt or by changing the $\mathrm{pH}$, temperature or by dilution of the medium. The shell thickness can be obtained as desired by 


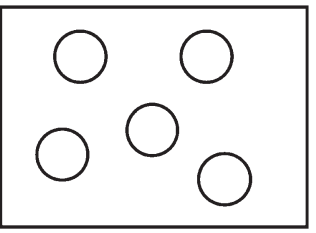

(a)
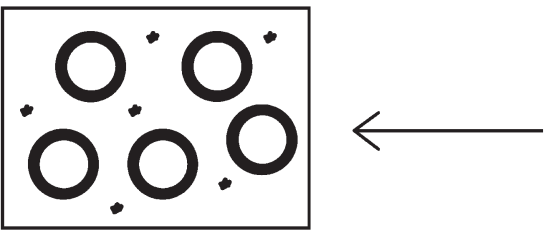

(d)

Figure 1.11 Schematic representation of the coacervation process. (a) Core material dispersion in solution of shell polymer; (b) separation of coacervate from solution; (c) coat-

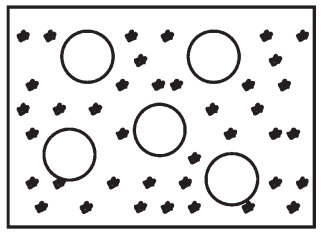

(b)

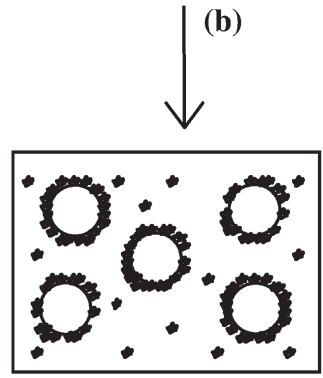

(c)

ing of core material by microdroplets of coacervate; (d) coalescence of coacervate to form continuous shell around core particles.

controlled addition of the second polymer. Finally, the prepared microcapsules are stabilized by crosslinking, desolvation or thermal treatment.

Complex coacervation is used to produce microcapsules containing fragrant oils, liquid crystals, flavors, dyes or inks as the core material. Porous microcapsules can also be prepared using this technique. When using this technique, certain conditions must be met to avoid agglomeration of the prepared capsules [93]. A micrograph of microcapsules prepared using the coacervation technique is shown in Figure 1.12.

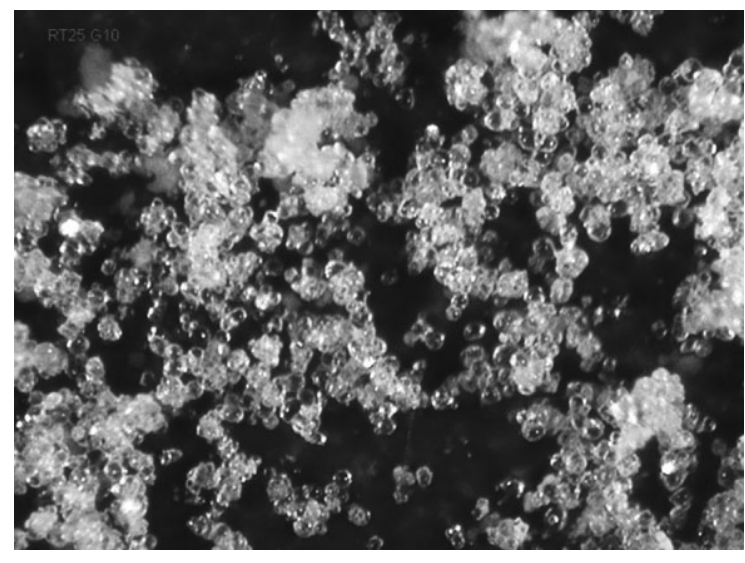

Figure 1.12 Gelatin microcapsules containing a phasechange material prepared by the coacervation method (Courtesy: G. Habar, Microcapsules-Technologies). 


\subsubsection{Encapsulation by Polyelectrolyte Multilayer}

Layer by layer (L-B-L) electrostatic assembly of electrically charged particles has attracted much attention due to its enormous potential in multilayered thin film preparations with a wide range of electrical, magnetic and optical properties [94-98]. Polyelectrolyte multilayers are the most widely studied examples of L-B-L assembly, and are prepared by sequentially immersing a substrate in positively and negatively charged polyelectrolyte solutions in a cyclic procedure. However, other charged particles such as nanoparticles, ionic dyes and metal ions are used for preparing L-B-L assembly. Core-shell particles with tailored size and properties are prepared using colloidal particle as the core material that serves as a template onto which multilayers are fabricated. Hollow capsules of organic, inorganic or hybrid particles can be obtained by dissolving the core material. This technique is both versatile and simple, with the multilayer film thickness being controlled precisely by varying the total number of layers deposited; in this way the final properties can be tuned. A detailed discussion of L-B-L assembly for microcapsule preparations is provided in Chapter 3.

\subsubsection{Polymer Encapsulation by Rapid Expansion of Supercritical Fluids}

Supercritical fluids are highly compressed gasses that possess several advantageous properties of both liquids and gases. These fluids have attracted much attention in recent years, the most widely used being supercritical $\mathrm{CO}_{2}$, alkanes $\left(\mathrm{C}_{2}\right.$ to $\left.\mathrm{C}_{4}\right)$, and nitrous oxide $\left(\mathrm{N}_{2} \mathrm{O}\right)$. They have low hydrocarbon-like solubility for most solutes and are miscible with common gases such as hydrogen $\left(\mathrm{H}_{2}\right)$ and nitrogen $\left(\mathrm{N}_{2}\right)$. A small change in temperature or pressure causes a large change in the density of supercritical fluids near the critical point - a property which enhances their use in several industrial applications. Supercritical $\mathrm{CO}_{2}$ is widely used for its low critical temperature value, in addition to its nontoxic, nonflammable properties; it is also readily available, highly pure and cost-effective. It has found applications in encapsulating active ingredients by polymers. Different core materials such as pesticides, pigments, pharmaceutical ingredients, vitamins, flavors, and dyes are encapsulated using this method [99-101]. A wide variety of shell materials that either dissolve (paraffin wax, acrylates, polyethylene glycol) or do not dissolve (proteins, polysaccharides) in supercritical $\mathrm{CO}_{2}$ are used for encapsulating core substances. The most widely used methods are as follows:

- Rapid expansion of supercritical solution (RESS)

- Gas anti-solvent (GAS)

- Particles from gas-saturated solution (PGSS)

\section{Rapid expansion of supercritical solution}

In this process, supercritical fluid containing the active ingredient and the shell material are maintained at high pressure and then released at atmospheric pressure through a small nozzle. The sudden drop in pressure causes desolvation of the shell material, which is then deposited around the active ingredient (core) and forms a coating layer. The disadvantage of this process is that both the active in- 


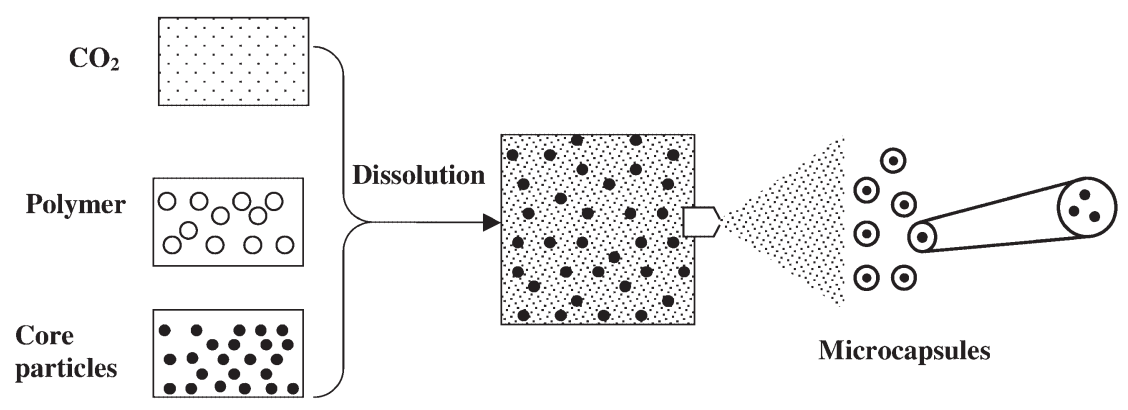

Figure 1.13 Microencapsulation by rapid expansion of supercritical solutions (RESS).

gredient and the shell material must be very soluble in supercritical fluids. In general, very few polymers with low cohesive energy densities (e.g., polydimethylsiloxanes, polymethacrylates) are soluble in supercritical fluids such as $\mathrm{CO}_{2}$. The solubility of polymers can be enhanced by using co-solvents. In some cases nonsolvents are used; this increases the solubility in supercritical fluids, but the shell materials do not dissolve at atmospheric pressure. A schematic of the microencapsulation process using supercritical $\mathrm{CO}_{2}$ is shown in Figure 1.13.

Kiyoshi et al. had very recently carried out microencapsulation of $\mathrm{TiO}_{2}$ nanoparticles with polymer by RESS using ethanol as a nonsolvent for the polymer shell such as polyethylene glycol (PEG), poly(styrene)-b-(poly(methylmethacrylate)-copoly(glycidal methacrylate) copolymer (PS-b-(PMMA-co-PGMA) and poly(methyl methacrylate) [102].

\section{Gas anti-solvent (GAS) process}

This process is also called supercritical fluid anti-solvent (SAS). Here, supercritical fluid is added to a solution of shell material and the active ingredients and maintained at high pressure. This leads to a volume expansion of the solution that causes supersaturation such that precipitation of the solute occurs. Thus, the solute must be soluble in the liquid solvent, but should not dissolve in the mixture of solvent and supercritical fluid. On the other hand, the liquid solvent must be miscible with the supercritical fluid. This process is unsuitable for the encapsulation of water-soluble ingredients as water has low solubility in supercritical fluids. It is also possible to produce submicron particles using this method.

\section{Particles from a gas-saturated solution (PGSS)}

This process is carried out by mixing core and shell materials in supercritical fluid at high pressure. During this process supercritical fluid penetrates the shell material, causing swelling. When the mixture is heated above the glass transition temperature $\left(T_{\mathrm{g}}\right)$, the polymer liquefies. Upon releasing the pressure, the shell material is allowed to deposit onto the active ingredient. In this process, the core and shell materials may not be soluble in the supercritical fluid. 
Within the pharmaceutical industry, preformed microparticles are often used for the entrapment of active materials using supercritical fluids under pressure. When the pressure is released, the microparticles shrink and return to their original shape and entrap the ingredients.

\section{9 .3}

\section{Physico-Mechanical Processes}

\subsubsection{Co-Extrusion}

The co-extrusion process was developed by Southwest Research Institute in the United States, and has found a number of commercial applications. A dual fluid stream of liquid core and shell materials is pumped through concentric tubes and forms droplets under the influence of vibration (Fig. 1.14). The shell is then hardened by chemical crosslinkings, cooling, or solvent evaporation. Different types of extrusion nozzles have been developed in order to optimize the process [103].

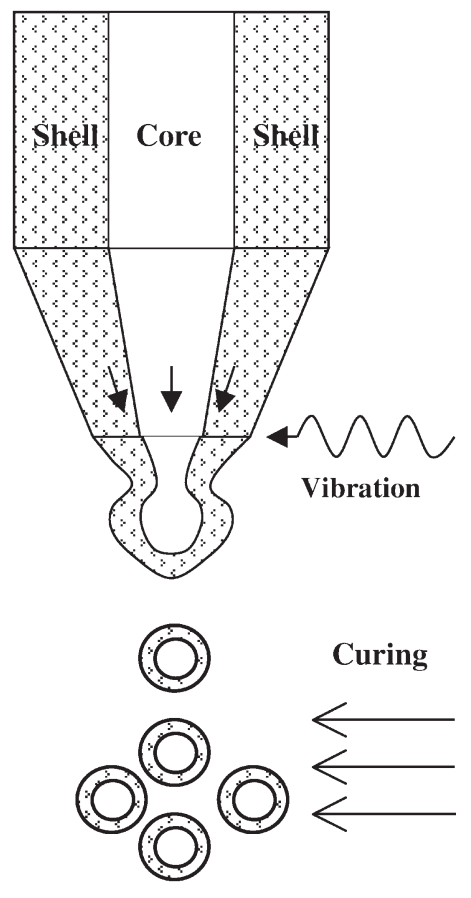

Figure 1.14 Schematic presentation of the coextrusion process.

\subsubsection{Spray-Drying}

Microencapsulation by spray-drying is a low-cost commercial process which is mostly used for the encapsulation of fragrances, oils and flavors. Core particles are dispersed in a polymer solution and sprayed into a hot chamber (Fig. 1.15). The shell material solidifies onto the core particles as the solvent evaporates such that the microcapsules obtained are of polynuclear or matrix type. Very often the en- 


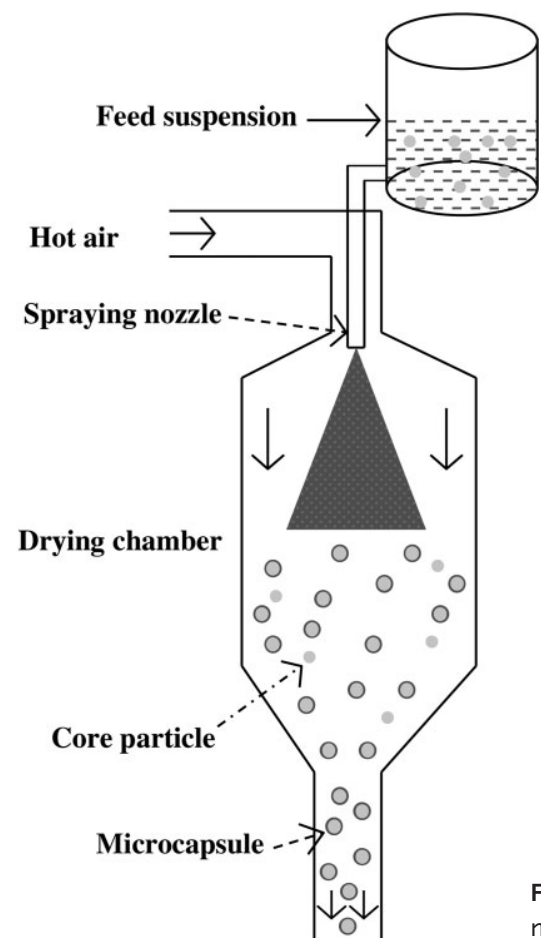

Figure 1.15 Schematic illustrating the process of micro-encapsulation by spray-drying.

capsulated particles are aggregated and the use of large amounts of core material can lead to uncoated particles. However, higher loadings of core particles of up to $50-60 \%$ have been reported [104]. Water-soluble polymers are mainly used as shell materials because solvent-borne systems produce unpleasant odors and environmental problems.

\subsubsection{Fluidized-Bed Technology}

With the high demand for encapsulated materials in the global market, fluid-bed coaters have become more popular. They are used for encapsulating solid or porous particles with optimal heat exchange [105]. The liquid coating is sprayed onto the particles and the rapid evaporation helps in the formation of an outer layer on the particles. The thickness and formulations of the coating can be obtained as desired. Different types of fluid-bed coaters include top spray, bottom spray, and tangential spray (Fig. 1.16).

- In the top spray system the coating material is sprayed downwards on to the fluid bed such that as the solid or porous particles move to the coating region they become encapsulated. Increased encapsulation efficiency and the prevention of cluster formation is achieved by opposing flows of the coating materials and the particles. Dripping of the coated particles depends on the formulation of the 

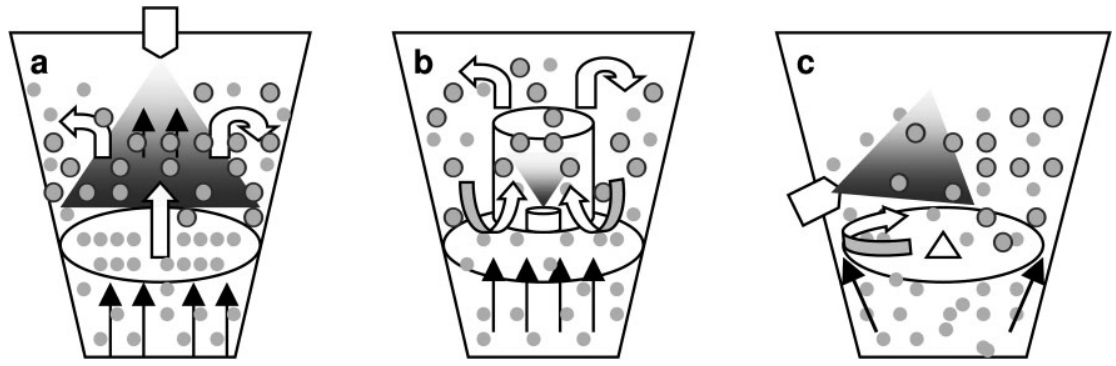

Figure 1.16 Schematics of a fluid-bed coater. (a) Top spray; (b) bottom spray; (c) tangential spray.

coating material. Top spray fluid-bed coaters produce higher yields of encapsulated particles than either bottom or tangential sprays.

- The bottom spray is also known as "Wurster's coater" in recognition of its development by Prof. D.E. Wurster [106]. This technique uses a coating chamber that has a cylindrical nozzle and a perforated bottom plate. The cylindrical nozzle is used for spraying the coating material. As the particles move upwards through the perforated bottom plate and pass the nozzle area, they are encapsulated by the coating material. The coating material adheres to the particle surface by evaporation of the solvent or cooling of the encapsulated particle. This process is continued until the desired thickness and weight is obtained. Although it is a timeconsuming process, the multilayer coating procedure helps in reducing particle defects.

- The tangential spray consists of a rotating disc at the bottom of the coating chamber, with the same diameter as the chamber. During the process the disc is raised to create a gap between the edge of the chamber and the disc. The tangential nozzle is placed above the rotating disc through which the coating material is released. The particles move through the gap into the spraying zone and are encapsulated. As they travel a minimum distance there is a higher yield of encapsulated particles.

\subsubsection{Spinning Disk}

The microencapsulation of suspended core materials using a rotating disc was first developed by Prof. R.E. Sparks [107]. A schematic diagram of the process is shown in Figure 1.17. Suspensions of core particles in liquid shell material are poured into a rotating disc and, due to the spinning action of the disc, the core particles become coated with the shell material. The coated particles, along with the excess shell material, are then cast from the edge of the disc by centrifugal force, after which the shell material is solidified by external means (usually cooling). This technology is rapid, cost-effective, relatively simple and has high production efficiencies. For optimum encapsulation, spherical core particles with diameters of $\sim 100$ to $150 \mu \mathrm{m}$ and rapidly cooling shell materials are required. 


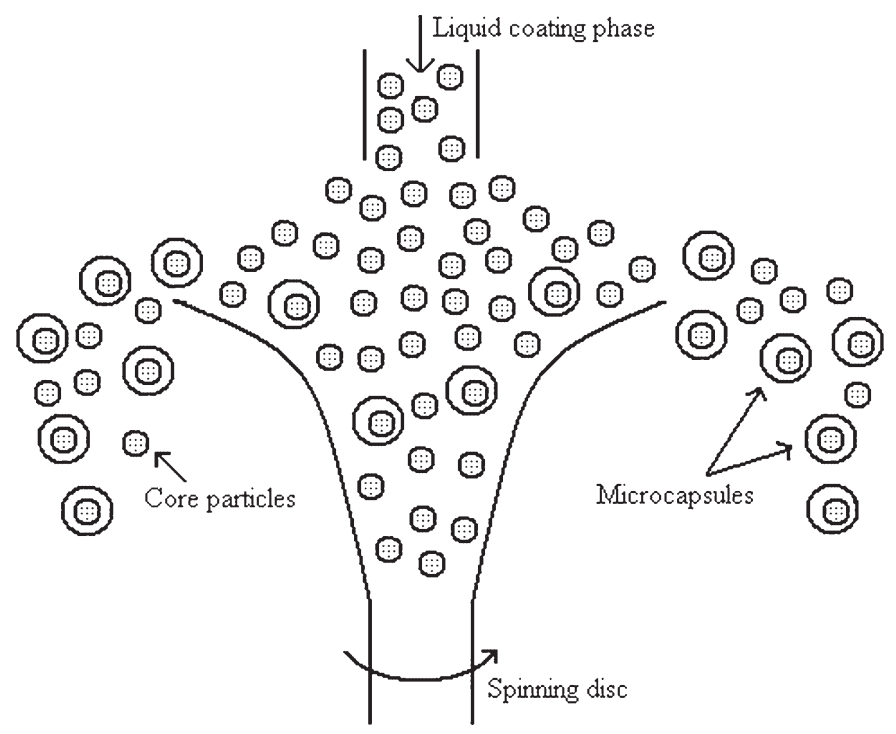

Figure 1.17 Schematic representation of microcapsule formation by spinning disk.

Although a variety of alternative microencapsulation techniques is available (for details of sol-gel techniques, see Chapter 8), no single method is suitable for encapsulating different types of core material. Ultimately, the best method will depend upon the type of core material, the required particle size, the permeability of the shell wall, and the different properties of the microcapsule, and consequently the process must be custom-tailored in order to provide a satisfactory outcome. An overview of the size of microcapsules obtained by different techniques is provided in Table 1.2.

Table 1.2 Microencapsulation processes with their relative particle size ranges.

\begin{tabular}{ll}
\hline Microencapsulation process & $\begin{array}{l}\text { Particle size } \\
{[\mu \mathrm{m}]}\end{array}$ \\
\hline Extrusion & $250-2500$ \\
Spray-drying & $5-5000$ \\
Fluid bed coating & $20-1500$ \\
Rotating disk & $5-1500$ \\
Coacervation & $2-1200$ \\
Solvent evaporation & $0.5-1000$ \\
Phase separation & $0.5-1000$ \\
In-situ polymerization & $0.5-1100$ \\
Interfacial polymerization & $0.5-1000$ \\
Miniemulsion & $0.1-0.5$ \\
Sol-gel encapsulation & $2-20$ \\
Layer-by-layer (LBL) assembly & $0.02-20$ \\
\hline
\end{tabular}




\subsection{0}

\section{Enhancing Coating Functionalities with Microcapsules}

Microcapsules can be used in a wide variety of applications [82,108,109], since the versatility of microencapsulation technologies offers unlimited combinations of core and shell materials for their production. To date, few investigations have been made into possible applications of microcapsules in functional coating developments. Microcapsules are applied onto substrates in various ways. For example, they may be sprayed over an existing coating layer, perhaps to provide immediate release of lubricants or perfumes. The most two common process of applying microcapsules in coatings are either to incorporate them into a coating formulation or by their electrolytic co-deposition with metal ions (Fig. 1.18; see also Chapter 9) $[110,111]$.

The mixing of microcapsules with coating binders require compatibility of the shell material with the binder. Generally, microcapsules are used in coatings for controlled-release applications, but microcapsules containing active ingredients such as biocides can also be trapped inside a coating matrix that will release the contents slowly over time. Another interesting example is to use microcapsules in the development of self-healing coatings [112]. For this, microcapsules containing monomer, crosslinker or catalysts are incorporated into a coating matrix such that, when a coating ruptures, the microcapsules along the rupture break open and release their contents. Subsequently, the monomer polymerizes, crosslinks, and fills the damage, thereby preventing further propagation. An innovative example is the use of microencapsulated phase-change material (PCM) particles in interior coatings for buildings $[113,114]$. During the day, as the temperature rises, the core material melts and stores heat. During the night, when the temperature falls, the heat stored inside the capsules is released, thereby reducing energy needs. Clearly, for

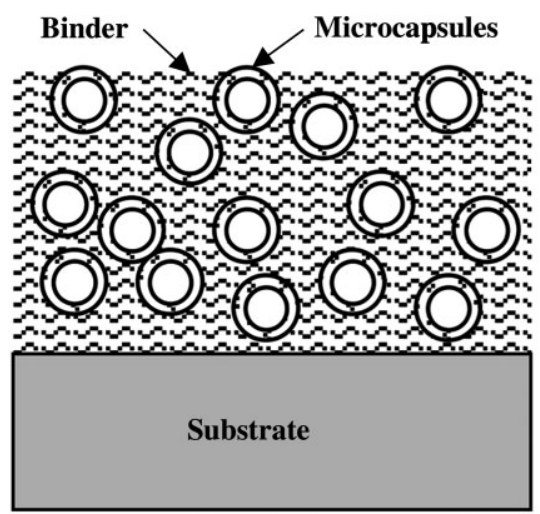

a)

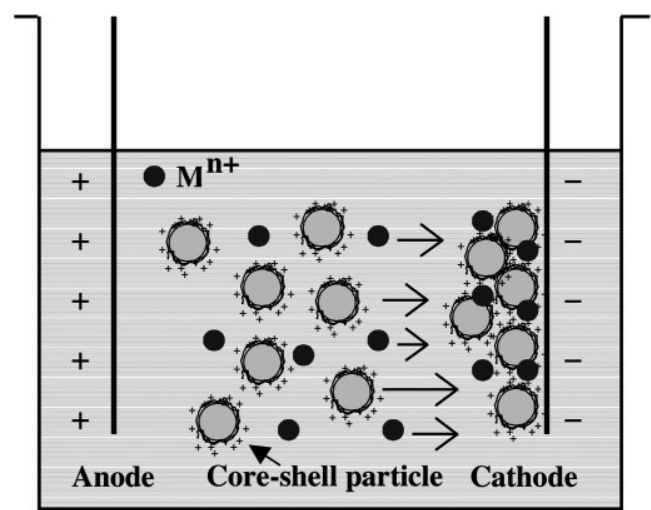

b)
Figure 1.18 Schematic diagram showing pathways for microcapsule incorporation into coatings. (a) Blending of microcapsules with binders; (b) electrolytic co-deposition of microcapsules with metallic ions. 
heat management to be effective, the correct quantities of microcapsules must be used in the preparation of such coatings. Other applications include microencapsulated dyes used to formulate color coatings, and foaming agents (e.g., sodium bicarbonate) which can be microencapsulated to generate foams during curing processes. Microcapsules containing perfumes, insecticides, chemicals, and heator pressure-sensitive dyes can also be used for functional coating preparations. The use of polymers with different $T_{g}$ values can be used to create microcapsules that can be added to coatings in order to produced specialized functions, for example vibration damping. Finally, microcapsules containing nanoparticles may be used in the design of functional surfaces with improved physical, optical, mechanical, electrical, or chemical properties.

\subsection{1}

\section{Conclusions}

Microencapsulation has already been proven as a successful technology for commercial applications in the pharmaceutical and agrochemical industries and, more recently, also in the textile industry. In general, however, the technology remains largely unexplored, notably in the field of functional coatings where the possibilities of obtaining functional surfaces using microcapsules are almost unlimited. The technology allows combinations to be made of the properties of different materials that are difficult or even impossible with other available technologies. The high cost of microencapsulation may often be a prohibitive factor, though in some cases it is justified by the added value of the products. As worldwide demands for functional coatings continue to increase, new, cost-effective microencapsulation technologies will be developed and the technology will remain at the forefront of future research. At present, the industry's major problem is to provide functional coatings that are easy to apply and have long-term stability; consequently, attention will be focused in this area.

\section{Abbreviations}

CB conduction band

GAS gas anti-solvent

ICP intrinsically conductive polymer

L-B-L layer by layer

PCM phase-change material

PGSS particles from gas-saturated solution

RESS rapid expansion of supercritical solution

SAS supercritical fluid anti-solvent

TBT tributyl tin

$T_{\mathrm{g}} \quad$ glass transition temperature

VB valence band 


\section{References}

1. Z.W. Wicks, Jr., F.N. Jones, S.P. Pappas, Organic Coatings: Science and Technology Vol. I, John Wiley \& Sons, Inc., New York, 1992, Chapter 1.

2. R. Lambourne, in: Paints and Surface Coatings, Theory and Practice (Eds. R. Lambourne, T.A. Strivens), 2nd edn. Chem Tech Pub. Inc., 1999, Chapter 1.

3. J.V. Koleske, in: Encyclopedia of Analytical Chemistry (Ed. R.A. Meyers), John Wiley \& Sons Ltd., Chichester, 2000, Chapter 4.

4. A.D. Wilson, J.W. Nicholson, H.J. Prosser, Surface Coatings-1, Elsevier Applied Science, New York, 1987, Chapter 1.

5. C.R. Hegedus, JCT Research 2004, 1(1), 5-19.

6. V.V. Verkholantsev, Eur. Coat. J. 2003, 9, 18-25.

7. M. Wulf, A. Wehling, O. Reis, Macromol. Symp. 2002, 187, 459-467.

8. I. P. Parkin, R. G. Palgrave, J. Mater. Chem. 2005, 15(17), 1689-1695.

9. E. Nun, M. Oles, B. Schleich, Macromol. Symp. 2002, 187, 677-682.

10. M. Kuhr, S. Bauer, U. Rothhaar, D. Wolff, Thin Solid Films 2003, 442 (1-2), 107-116.

11. M. Perez, M. Garcia, B. del Amo, G. Blustein, M. Stupak, Surf. Coat. Int. Part B Coat. Trans. 2003, 86 (4), 259-262.

12. L.C. Zhou, B. Koltisko, Jct. Coatingstech. 2005, 2(15), 54-60.

13. J.C. Tiller, C.J. Liao, K. Lewis, A.M. Klibanov, Proc. Natl. Acad. Sci. USA 2001, 98(11), 5981-5985.

14. K. Johns, Surf. Coat. Int. Part B: Coat. Trans. 2003, 86 (B2), 91-168.

15. http://www.agion-tech.com.

16. V.V. Verkholantsev, Eur. Coat. J. 2003, 10, 32-37.

17. P.J. Gellings, Introduction to corrosion prevention and control, Delft University Press, 1985.

18. C.I. Elsner, E. Cavalcanti, O. Ferraz, A.R. Di Sarli, Prog. Org. Coat. 2003, 48, 50-62.

19. N. Kouloumbi, P. Moundoulas, Pigment \& Resin Technol. 2002, 31(4), 206-215.

20. N. Kouloumbi, P. Pantazopoulou, P. Moundoulas, Pigment \& Resin Technol. 2003, 32(2), 89-99.

21. L. Hochmannov, Eur. Coat. J. 2003, 9, 26-32.
22. Jui-Ming Yeh, Shir-Joe Liou, Chih-Guang Lin, Yen-Po Chang, Yuan-Hsiang Yu, ChiFeng Cheng, J. Appl. Polym. Sci. 2004, 92, 1970-1976.

23. V. Palanivel, W.J. Van Ooij, in: Silanes and Other Coupling Agents (Ed. K.L. Mittal), Volume 3, VSP, 2004, pp. 135-159.

24. S. Monte, Polymer Paint Color J. December 2003.

25. M. Kendig, M. Hon, L. Warren, Prog. Org. Coat. 2003, 47, 183-189.

26. M. Kraljic, Z. Mandic, Lj. Duic, Corr. Sci. 2003, 45, 181-198.

27. T. Rentschler, A. Claßen, Eur. Coat. J. 2002, 9, 24-27.

28. A. Kumar, L.D. Stephenson, Coat. World 2004, 24-26 \& 28-33.

29. D. Bhattacharya, Worldwide, WO03093380, November 13, 2003.

30. D.L. Gangotri, A.D. Chaware, Paint India September 2004, 39-42.

31. G. Camino, R. Delobel, in: Fire Retardance of Polymeric Materials (Ed. C.A. Wilkie, A.F. Grand) Chapter 7, Marcel Dekker, Inc., New York, 2000, pp. 217-243.

32. F.J.W.J. Labuschagné, Metal catalysed intumescence of polyhydroxyl compounds, $\mathrm{PhD}$ Thesis, University of Pretoria, 2003.

33. K. Rathberger, Addconworld 2004, Amsterdam, Rapra Conference Proceedings, Paper 11 .

34. S. Girand, S. Bourbigot, M. Rochery, I. Vroman, L. Tighzert, R. Delobel, Polym. Degrad. Stab. 2002, 77(2), 285-297.

35. T. Kashiwagi, J.W. Gilman, in: Fire Retardance of Polymeric Materials (Ed. C.A. Wilkie, A.F. Grand), Chapter 10, Marcel Dekker, Inc., New York, 2000, pp. 353-389.

36. W.E. Horn, Jr., in: Fire Retardance of Polymeric Materials (Ed. C.A. Wilkie, A.F. Grand), Chapter 9, Marcel Dekker, Inc., New York, 2000, pp. 285-332.

37. B. Kandola, S. Nazaré, R. Horrocks and various papers, in: Fire and Polymers, Polym. Mater. Sci. Eng. Preprints, American Chemical Society, August 22-26, 2004.

38. M. Zanetti, S. Lomakin, G. Gamino, Macromol. Mater. Eng. 2000, 279, 1-9.

39. T. Sawitowski, K. Schulte, Nano and Hybrid Coatings, PRA Coatings Technology, 
24-25 January 2005, Manchester, UK, Paper no. 8.

40. D.R. Baer, P.E. Burrows, A.A. El-Azab, Prog. Org. Coat. 2003, 47, 342-356.

41. H.J. Gläsel, F. Bauer, H. Ernst, M. Findeisen, E. Hartmann, H. Langguth, R. Mehnert, R. Schubert, Macromol. Chem. Phys. 2000, 201, 2765-2770.

42. R. Mehnert, E. Hartmann, H.J. Glasel. S. Rummel, F. Bauer, A. Sobottka, Ch. Elsner, Mat. -wiss. U. Werkstofftech. 2001, 32, 774-780.

43. G.A. Lawrence, A.K. Barkac, M.A. Chasser, A.S. Desaw, E.M. Hartman, E. Mavis, E.D. Hayes, R.T. Hockswender, L.K. Kuster, A.R. Montague, M. Nakajima, G.K. Olson, S.J. Richardson, J.R. Sadvari, A.D. Simpson, S. Tyebjee, F.T. Wilt, US Patent 6387519, May 14, 2002.

44. F.A.P. Thomas, J.A.W. Stoks, A. Buegman, US Patent 6291054, September 18, 2001.

45. http://www.nano-x.de/index.html

46. W. Barthlott, C. Neinhuis, Planta 1997, 202, 1-8.

47. A. Nakajima, K. Hashimoto, T. Watanabe, Monatshefte für Chemie 2001, 132, 31-41.

48. R. Blossey, Nature Materials 2003, 2, 301-306.

49. I.P. Parkin, R.G. Palgrave, J. Mater. Chem. 2005, 15(17), 1689-1695.

50. Y.T. Cheng, D. Rodak, Appl. Phys. Lett. 2005. 86 (144101) 1-3.

51. A. Fujishima, K. Hashimoto, T. Watanabe, $\mathrm{TiO}_{2}$ Photocatalysis: Fundamentals and Applications. BKC, Tokyo, 1999, p. 66.

52. T. Watanabe, Bull. Ceram. Soc. Jpn. 1996, 31, 837-840.

53. A. Fujishima, T.A. Rao, D.A. Tyrk, J. Photochem. Photobiol. C: Photochem. Rev. 2000, 1, 1-21.

54. K. Guan, Surf. Coat. Technol. 2005, 191, 155-160.

55. A. Nakajima, K.Hashimoto, T. Watanabe, K. Takai, G. Yamauchi, A. Fujishima, Langmuir 2000, 16, 7044-7047.

56. N. Niegisch, M. Akarsu, Z. Csögör, M.Ehses, H. Schmidt, Hygienic Coatings, Brussels, Belgium, 8-9 July 2002, paper 20.

57. G. Yamauchi, Y. Riko, Y. Yasuno, T. Shimizu, N. Funakoshi, Nano and Hybrid Coatings, The Paint Research Association,
Manchester, UK, 24-25 January 2005, paper 20.

58. J. Ross, Polymer Paint Color J. 2004, 194 (4479), 18-20.

59. D. Thölmann, B. Kossmann, F. Sosna, Eur. Coat. J. 2003, 1(2), 16-33.

60. G. Sauvet, S. Dupond, K. Kazmierski, J. Chojnowski, J. Appl. Polym. Sci. 2003, 75, 1005-1012.

61. A.J. Trogolo, C.F. Rossitto, K.E. Welch, II, World Patent, WO 03/055941, July 10 , 2003.

62. M. Wagener, Hygienic Coatings a Surfaces, PRA Coatings Technology Centre, Paris, 16-17 March 2005, paper 14.

63. T. Xu, C.S. Xie, Prog. Org. Coat. 2003, 46, 297-301.

64. G. Borkow, Hygienic Coatings \& Surfaces, PRA Coatings Technology Centre, Paris, 16-17 March 2005, paper 20.

65. E.J. Wolfrum, J. Huang, D.M. Blake, P.C. Maness, Z. Huang, J. Fiest, W.A. Jacoby, Environ. Sci. Technol. 2002, 36, 3412-3419.

66. B. Windsor, Hygienic Coatings Q 2 Surfaces, PRA Coatings Technology Centre, Paris, 16-17 March 2005, paper 23.

67. J.C. Kim, M.E. Song, E.J. Lee, S.K. Park, M.J. Rang, H.J. Ahn, J. Dispersion Sci. Technol. 2001, 22(6), 591-596.

68. M. Edge, N.S. Allen, D. Turner, J. Robinson, K. Seal, Prog. Org. Coat. 2001, 43, 10-17.

69. S.D. Worley, F. Li, R. Wu, J. Kim, C.I. Wei, J.F. Williams, J.R. Owens, J.D. Wander, A.M. Bergmeyer, M.E. Shirtliff, Surf. Coat. Inter. Part B: Coat. Trans. 2003, 86(4), 273-277.

70. M. Thouvenin, J.J. Peron, C. Charreteur, P. Guerin, J.Y. Langlois, K. Valle-Rehel, Prog. Org. Coat. 2002, 44, 75-83.

71. M. Perez, M. Garcia, B. del Amo, G. Blustein, M. Stupak, Surf. Coat. Inter. Part B: Coat. Trans. 2003, 86(4), 259-262.

72. H. Gold, D.R. Levy, M. Temchenko, H.E.T Mendum, T. Tanaka, T. Enoki, G. Wang, European Patent EP 1406732, April 14, 2004.

73. G. Wagner, Eur. Coat. J. 2002, 7/8, 44-47.

74. J.R. White, B. De Poumeyrol, J.M. Halle, R. Stepheson, J. Mater. Sci. 2004, 39, 3105-3114.

75. M. Pridöhl, S. Heberer, R. Maier, R. Mertsch, G. Michael, European Coatings Conference: Smart Coatings III., 
Berlin, Germany, 7-8 January 2004, 141-148.

76. A. Sen, R. Pandey, Paintindia 2001, Golden Jubilee Issue, 143-156.

77. A.R. Hemsley, P.C. Griffiths, Philos. Trans. R. Soc. London Ser. 2000, 358, 547 - 564.

78. L. Schleicher, B.K. Green, US Patent 2730456, 1956.

79. M.M. Gutcho, Microcapsules and Microencapsulation Techniques, Noyes Data Co., New Jersey, USA, 1976.

80. J.E. Vandegaer, Microencapsulation: Processes and Applications, Plenum Press, New York, 1973.

81. S. Benita, Microencapsulation: Methods and Industrial applications, Marcel Dekker, Inc., New York, 1996.

82. R. Arshady, Microspheres, Microcapsules and Liposomes, Citrus Books, London, United Kingdom, 1999.

83. W. Sliwka, Angew. Chem. Int. Ed. 1975, 14(8), 539-550.

84. M.W. Ranney, Microencapsulation Technology, Noyes Development Corporation, Park Ridge, 1969, p. 275.

85. J.L. Luna-Xavier, E. Bourgeat-Lami, A. Guyot, Colloid. Polym. Sci. 2001, 279, 947-958.

86. W.F. Liu, Z.X. Guo, J. Yu, J. Appl. Polym. Sci. 2005, 97(4), 1538-1544.

87. M. Okubo, H. Minami, Y. Jing, J. Appl. Polym. Sci. 2003, 89, 706-710.

88. M.L.Soto-Portas, J.F. Argillier, F. Méchin, N. Zydowicz, Polym. Int. 2003, 52, 522-527.

89. B.Z. Putlitz, K. Landfester, H. Fischer, M. Antonietti, Adv. Mater. 2001, 13(7), 500-503.

90. A.J.P. van Zyl, R.D. Sanderson, D. de WetRoos, B. Klumperman, Macromolecules 2003, 36, 8621-8629.

91. G. Bungenberg de Jong, H. Kruyt, Prog. Kungl. Ned. Acad. Wetensch. 1929, 32, 849-856.

92. H.G. Bungenberg de Jong, in: Colloid Science (Ed. H.R. Kruyt), Elsevier, 1949, pp. 232-258.

93. J. Okada, A. Kusai, S. Ueda, J. Microencapsulation 1985, 2, 163-173.
94. G. Decher, Science 1997, 277, 1232-1237.

95. M. Freemantle, Chem. Eng. News 2002, 80 (18), 44-48.

96. C.S. Peyratout, L. Dähne, Angew. Chem. Int. Ed. 2004, 43, 3762-3783.

97. G.B. Sukhorukov, A. Fery, M. Brumen, H. Möhwald, Phys. Chem. Chem. Phys. 2004, 6, 4078-4089.

98. D. Lee, M.F. Rubner, R.E. Cohen, Chem. Mater. 2005, 17, 1099-1105.

99. R. Ghaderi, A Supercritical Fluids Extraction Process for the Production of Drug Loaded Biodegradable Microparticles, PhD Thesis, ACTA Universitatis Upasaliensis, Uppsala, 2000.

100. H. Liu, M.Z. Yates, Langmuir 2002, 18, 6066-6070.

101. P. Chambon, E. Cloutet, H. Cramail, Macromolecules 2004, 37, 5856-5859.

102. K. Matsuyama, K. Mishima, K.I. Hayashi, H. Matsuyama, J. Nanoparticle Res. 2003, 5, 87-95.

103. J.T. Goodwin, G.R. Somerville, Chemtech. 1974, 623-626.

104. J. Brener, Perfumer and Flavorist 1983, 8, 40-44.

105. K. Lehmann, in: Microcapsules and Nanoparticles in Medicine and Pharmacy (Ed. M. Donbrow), CRC Press, Boca Raton, 1992, pp. 73-97.

106. D.E. Wurster, US Patent 2648609 , September 8, 1953.

107. R.E. Sparks, M. Norbert, US Patent 4675140, June 6, 1987.

108. G.O. Fanger, Chemtech. 1974, 397-405.

109. H. Yoshizawa, KONA 2004, 22, 23-31.

110. A. Dietz, M. Jobmann, G. Rafler, Mat.wiss. u. Werkstofftech. 2000, 31, 612-615.

111. Z. Liqun, Z. Wei, L. Feng, J. Mater. Sci. 2004, 39, 495-499.

112. E.N. Brown, S.R. White, N.R. Sottos, J. Mater. Sci. 2004, 39, 1703-1710.

113. J.F. Su, L.X. Wang, L. Ren, J. Appl. Polym. Sci. 2005, 97(5), 1755-1762.

114. M.N.A. Hawlader, M.S. Uddin, H.J. Zhu, Int. J. Energy Res. 2002, 26, 159-171. 